Article

\title{
Water Deficit and Heat Affect the Tolerance to High Illumination in Hibiscus Plants
}

\author{
Romualdo Muñoz and María José Quiles * \\ Department of Plant Biology, University of Murcia, 30100 Espinardo Murcia, Spain; \\ E-Mail: rmunoz@um.es \\ * Author to whom correspondence should be addressed; E-Mail: mjquiles@um.es; \\ Tel.: +34-868-884-947; Fax: +34-868-883-963.
}

Received: 22 January 2013; in revised form: 1 March 2013 / Accepted: 4 March 2013 /

Published: 7 March 2013

\begin{abstract}
This work studies the effects of water deficit and heat, as well as the involvement of chlororespiration and the ferredoxin-mediated cyclic pathway, on the tolerance of photosynthesis to high light intensity in Hibiscus rosa-sinensis plants. Drought and heat resulted in the down-regulation of photosynthetic linear electron transport in the leaves, although only a slight decrease in variable fluorescence $\left(\mathrm{F}_{\mathrm{v}}\right) /$ maximal fluorescence $\left(\mathrm{F}_{\mathrm{m}}\right)$ was observed, indicating that the chloroplast was protected by mechanisms that dissipate excess excitation energy to prevent damage to the photosynthetic apparatus. The incubation of leaves from unstressed plants under high light intensity resulted in an increase of the activity of electron donation by nicotinamide adenine dinucleotide phosphate (NADPH) and ferredoxin to plastoquinone, but no increase was observed in plants exposed to water deficit, suggesting that cyclic electron transport was stimulated by high light only in control plants. In contrast, the activities of the chlororespiration enzymes (NADH dehydrogenase (NDH) complex and plastid terminal oxidase (PTOX)) increased after incubation under high light intensity in leaves of the water deficit plants, but not in control plants, suggesting that chlororespiration was stimulated in stressed plants. The results indicate that the relative importance of chlororespiration and the cyclic electron pathway in the tolerance of photosynthesis to high illumination differs under stress conditions. When plants were not subjected to stress, the contribution of chlororespiration to photosynthetic electron flow regulation was not relevant, and another pathway, such as the ferredoxin-mediated cyclic pathway, was more important. However, when plants were subjected to water deficit and heat, chlororespiration was probably essential.
\end{abstract}


Keywords: chlororespiration; NDH complex; Hibiscus rosa-sinensis; PGR5; PTOX

\begin{abstract}
Abbreviations: DW, dry weight; ETR, relative electron transport rate; $\mathrm{F}_{\mathrm{m}}$, maximal fluorescence yield in the dark adapted state; $\mathrm{F}_{0}$, minimal fluorescence yield in the dark adapted state; $\mathrm{F}_{\mathrm{v}}$, variable fluorescence; $\mathrm{FW}$, fresh weight; NDH, NADH dehydrogenase; NADH-PQR, NADH-plastoquinone oxidoreductase; PAM, pulse amplitude modulation; PPFD, photosynthetic photon flux density; PS, photosystem; PTOX, plastid terminal oxidase; ROS, reactive oxygen species; RWC, relative water content; TW, turgid weight.
\end{abstract}

\title{
1. Introduction
}

Environmental stresses, such as high irradiance, high temperature and drought, negatively affect photosynthetic processes [1-3]. Plants are frequently exposed to stress, both in natural and agricultural conditions, and such exposure plays a major role in determining the distribution of plant species across different types of environment and in limiting crop productivity. Understanding the physiological processes that underlie stress injury and the tolerance mechanisms of plants to environmental stress is of immense importance to both agriculture and the environment.

Tolerance to stress results from integrated events occurring at all organization levels, from anatomical and morphological, to cellular, biochemical and molecular levels. At the biochemical level, plants alter their metabolism in various ways to accommodate environmental stress, and photosynthesis is one of these ways.

Photosynthesis in chloroplasts involves a vectorial electron transfer from water in the lumen to nicotinamide adenine dinucleotide phosphate $\left(\mathrm{NADP}^{+}\right)$in the stroma, by means of redox carriers. Besides this major pathway, alternative electron transfer pathways, involving non-photochemical reduction or the oxidation of plastoquinones at the expense of stromal electron donors or acceptors, have been proposed based on functional measurements. These additional reactions cover two main concepts, one based on the cycling of electrons around PS I [4-6] and the other on chlororespiration [7,8], which consists of electron transfer reactions from stromal reductants to $\mathrm{O}_{2}$ through the plastoquinone pool $[5,9,10]$.

Two thylakoidal enzymes, both of which are important in chlororespiration, have been molecularly characterized: the plastid-encoded NADH dehydrogenase (NDH) complex [11-16] and the nucleus-encoded plastid-localized terminal oxidase (PTOX) [17-19]. The NDH complex is an entry point for electrons into the photosynthetic electron-transport chain, involving the non-photochemical reduction of plastoquinones and PTOX as a point of electron transfer from plastoquinol to molecular oxygen, resulting in the formation of water in the stroma and reducing the formation of reactive oxygen species [9]. In addition to chlororespiration, the NDH complex is involved in the cyclic electron flow around PS I [20]. Two parallel cyclic pathways exist around PS I [20], one involving the NDH complex and the other sensitive to antimycin A, in which two proteins are essential components: the thylakoid membrane protein encoded by the pgr5 gene (PGR5) and the thylakoid transmembrane protein (PGRL1), which interacts functionally and physically with PGR5 [21-23]. The physiological role of the chloroplast electron pathways operating around PS I has been difficult to establish. 
Although these reactions probably do not play a major role during photosynthesis under optimal conditions [24-27], they probably participate in the flexibility of electron transfer reactions required to balance ATP/NADPH requirements when photosynthesis operates under changing environmental conditions [10,28-33].

Several studies have proposed that chlororespiratory components may be involved in the protective or adaptive mechanisms of plants in response to environmental stress, such as heat, water deficit and high light [17,34-45]. Recently, we described the increase in the NDH complex and PTOX in Spathiphyllum wallisii, a shade species very sensitive to heat and high illumination, when the above mentioned stresses were combined with water deficit [44]. Additionally, the involvement of the NDH-mediated cyclic electron pathways around PS I in supplying the extra adenosine triphosphate (ATP) required in conditions of mild water stress has been suggested [10]. These results suggested that the NDH complex and PTOX are heat and water stress dependent. However, the cooperation of the cyclic electron pathways and chlororespiration, under stress conditions, in photosynthesis remains unclear [11]. Additional experiments are needed to elucidate the relative importance of these pathways in the tolerance of photosynthesis to high illumination under stress caused by drought. The present work studies the effects of water deficit and heat, as well as the involvement of chlororespiratory enzymes and ferredoxin-mediated cyclic electron flow on the tolerance of photosynthesis to high light intensity in Hibiscus rosa-sinensis plants.

\section{Results}

\subsection{Changes in the Relative Water Content and in Fluorescence Parameters}

Plant water status was estimated by measuring the relative water content (RWC) of leaves in plants at the start of the experiment (control) and immediately after exposure to three photoperiods with reduced irrigation and heat (Figure 1). The RWC decreased to around 50\% after three stress photoperiods with low watering levels.

Figure 1. The relative water content (RWC) of leaves from H. rosa-sinensis plants at the start of the experiment (control) and after exposure to three photoperiods $(18 \mathrm{~h}$, $60 \mu \mathrm{mol} \cdot \mathrm{m}^{-2} \cdot \mathrm{s}^{-1}$ photosynthetic photon flux density (PFFD) and $35{ }^{\circ} \mathrm{C}$ ) with reduced irrigation (water deficit). The stress photoperiods were separated by $6 \mathrm{~h}$ night-periods at $24{ }^{\circ} \mathrm{C}$. The values are the means \pm SE from four independent replicates.

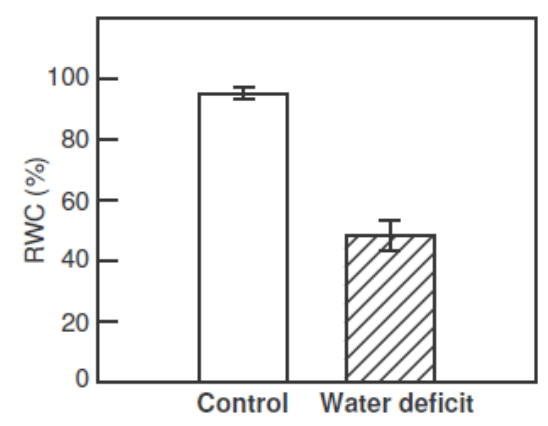


The fluorescence imaging technique was used to assess the maximal quantum yield of PS II (variable fluorescence $\left(\mathrm{F}_{\mathrm{v}}\right)$ /maximal fluorescence $\left(\mathrm{F}_{\mathrm{m}}\right)$ ) in intact leaves from plants in control conditions and when exposed to three photoperiods with reduced irrigation and heat (Figure 2). The results are shown as color-coded images and as histograms of the mean $\mathrm{F}_{\mathrm{v}} / \mathrm{Fm}$ values $\pm \mathrm{SE}$. After the three stress photoperiods, the $\mathrm{F}_{\mathrm{v}} / \mathrm{F}_{\mathrm{m}}$ decreased by around $5 \%$.

Figure 2. Images of the maximal quantum yield of PS II (variable fluorescence $\left(\mathrm{F}_{\mathrm{v}}\right) /$ maximal fluorescence $\left.\left(\mathrm{F}_{\mathrm{m}}\right)\right)$ from a typical leaf of $H$. rosa-sinensis plants in control conditions and after exposure to three photoperiods $\left(18 \mathrm{~h}, 60 \mu \mathrm{mol} \cdot \mathrm{m}^{-2} \cdot \mathrm{s}^{-1}\right.$ PPFD and $35^{\circ} \mathrm{C}$ ) with reduced irrigation (water deficit). The stress photoperiods were separated by $6 \mathrm{~h}$ night-periods at $24{ }^{\circ} \mathrm{C}$. The images are color-coded according to the pattern ( 0 to $1 \times 100$ range) shown below the images. The figure shows representative images from four independent experiments. The histograms show the means $\pm \mathrm{SE}$ from four independent replicates.
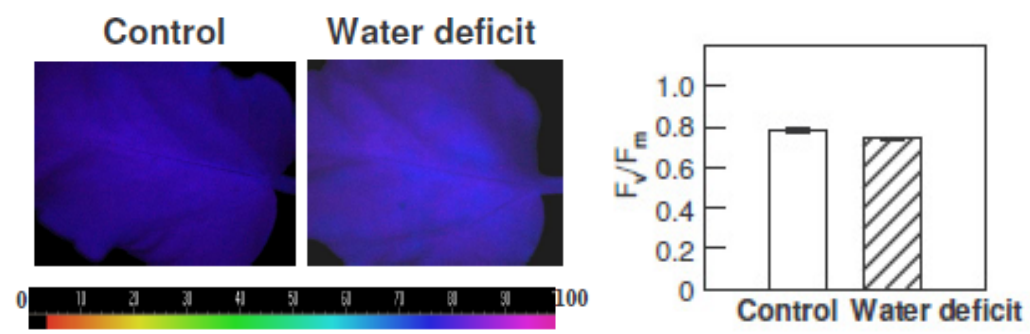

The light response curves for the quantum yield of PS II and the relative electron transport rate in intact leaves from control plants and plants exposed to water deficit and heat were studied using the fluorescence imaging technique (Figure 3). The PS II quantum yields and the relative electron transport rates decreased (by approximately $39 \%$ and $42 \%$, respectively) in plants exposed to water deficit and heat.

Figure 3. Light response curves for the quantum yield of PS II and the relative electron transport rate (ETR) in intact dark adapted leaves from Hibiscus rosa-sinensis plants in control conditions (white circles) and after exposure to three photoperiods $(18 \mathrm{~h}$, $60 \mu \mathrm{mol} \cdot \mathrm{m}^{-2} \cdot \mathrm{s}^{-1}$ PPFD and $35^{\circ} \mathrm{C}$ ) with reduced irrigation (black circles). The stress photoperiods were separated by $6 \mathrm{~h}$ night-periods at $24{ }^{\circ} \mathrm{C}$. The values are means $\pm \mathrm{SE}$ from five independent replicates.

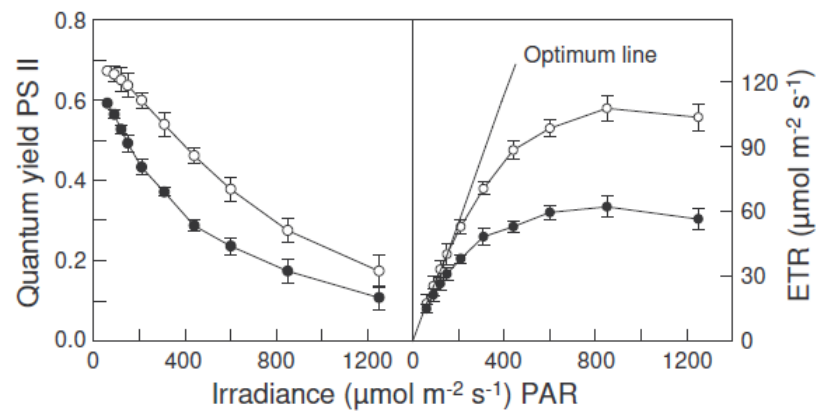




\subsection{Electron Donation to Plastoquinone in Osmotically Ruptured Chloroplasts}

The activity of electron donation by NADPH and ferredoxin to plastoquinone was assayed as an increase in the chlorophyll fluorescence emitted during exposure to light of a very low intensity $\left(1.0 \mu \mathrm{mol} \mathrm{m} \mathrm{m}^{-2} \mathrm{~s}^{-1}\right)$. The fluorescence level reflects the reduction of plastoquinone by electron transport from ferredoxin [21]. Chlorophyll fluorescence increased after the addition of NADPH (0.25 mM) and ferredoxin $(5 \mu \mathrm{M})$ under weak measuring light (Figure 4) in thylakoid membrane suspensions $\left(50 \mu \mathrm{g} \mathrm{Chl} \mathrm{mL}^{-1}\right)$ isolated from chloroplasts of leaves recently detached (Figure 4A,B) or incubated in water for $20 \mathrm{~h}$ under high light intensity $\left(1400 \mu \mathrm{mol} \mathrm{m} \mathrm{m}^{-2} \mathrm{~s}^{-1}\right)$ at $24{ }^{\circ} \mathrm{C}$ (Figure $\left.4 \mathrm{C}, \mathrm{D}\right)$. Thylakoid suspensions from leaves incubated in water for $20 \mathrm{~h}$ were additionally incubated with antimycin A $(2 \mu \mathrm{M})$ for $2 \mathrm{~min}$ prior to the measurements (Figure 4E,F). Control leaves incubated under high light intensity showed a greater increase of chlorophyll fluorescence (53\%) than control leaves recently detached (20\%). However, leaves from plants exposed to water deficit and heat, both recently detached and incubated under high light intensity, showed similar chlorophyll fluorescence levels $(20 \%$ and $23 \%$, respectively). Antimycin A inhibited the increase of chlorophyll fluorescence compared with measurements made without inhibitor, although its effect on leaves from plants exposed to water deficit and heat was slight (Figure 4F).

Figure 4. Increases in chlorophyll fluorescence after addition of nicotinamide adenine dinucleotide phosphate (NADPH) $(0.25 \mathrm{mM}) 30 \mathrm{~s}$ into the run and ferredoxin $(\mathrm{Fd}, 5 \mu \mathrm{M})$ $60 \mathrm{~s}$ into the run, under weak measuring light $\left(1.0 \mu \mathrm{mol} \cdot \mathrm{m}^{-2} \cdot \mathrm{s}^{-1}\right)$ in thylakoid membranes $\left(50 \mu \mathrm{g} \mathrm{Chl} \cdot \mathrm{mL}^{-1}\right)$ isolated from recently detached leaves (A and $\left.\mathbf{B}\right)$ or leaves incubated in water for $20 \mathrm{~h}$ under high light intensity $\left(1400 \mu \mathrm{mol} \cdot \mathrm{m}^{-2} \cdot \mathrm{s}^{-1}\right)$ at $24{ }^{\circ} \mathrm{C}(\mathbf{C}$ and $\mathbf{D})$. The leaves were detached from $H$. rosa-sinensis plants in control conditions and after exposure to three photoperiods $\left(18 \mathrm{~h}, 60 \mu \mathrm{mol} \cdot \mathrm{m}^{-2} \cdot \mathrm{s}^{-1}\right)$ PPFD and $35^{\circ} \mathrm{C}$ with reduced irrigation (water deficit). The stress photoperiods were separated by $6 \mathrm{~h}$ night-periods at $24{ }^{\circ} \mathrm{C}$. Thylakoid suspensions from leaves incubated in water for $20 \mathrm{~h}$ were additionally incubated with antimycin A $(2 \mu \mathrm{M})$ for 2 min prior to the measurements ( $\mathbf{E}$ and $\mathbf{F})$. The figure shows typical curves and the histograms of the means \pm SE from five independent replicates.
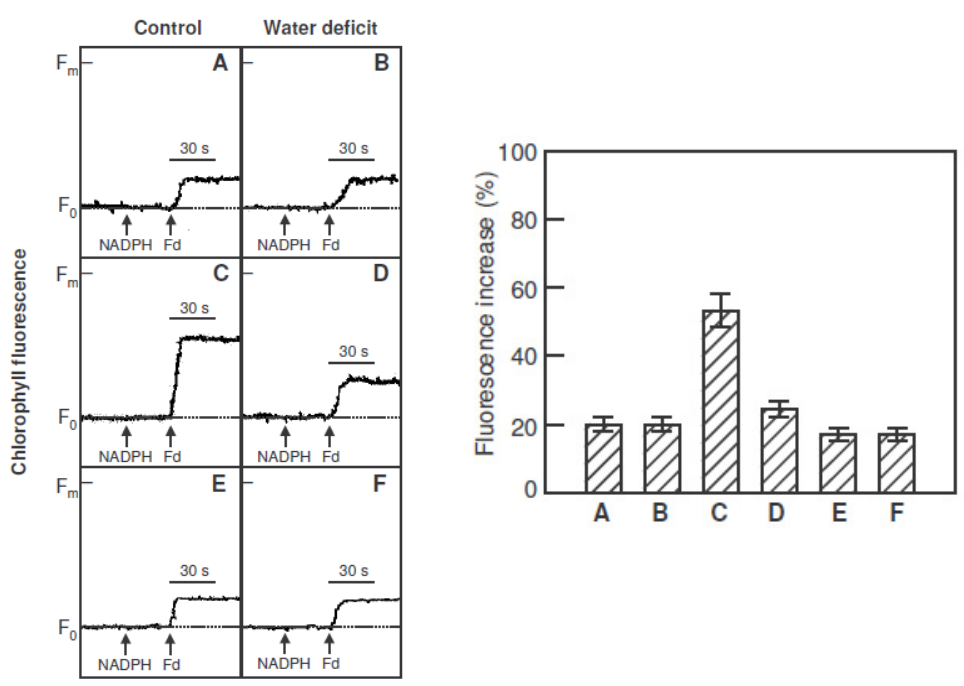


\subsection{PTOX and NADH-PQR Activities in the Thylakoid Membranes}

The PTOX activity in plastoquinone oxidation was assayed in recently isolated thylakoid membranes, as described by Joët et al. [46]. These authors observed that the addition of exogenous $2 \mathrm{mM}$ NADH and the PTOX inhibitor $1 \mathrm{mM} n$-propyl gallate to thylakoid suspensions increased the apparent $\mathrm{F}_{0}$ chlorophyll fluorescence level measured under low non-actinic light, because the reduced state of the plastoquinone pool increased. The redox state of the plastoquinone pool was the result of competition between reduction by the NDH complex and oxidation by the PTOX. Chlorophyll fluorescence increased after the addition of $2 \mathrm{mM} \mathrm{NADH}$ and $1 \mathrm{mM} n$-propyl gallate under low measuring light (Figure 5) in thylakoid membrane suspensions $\left(50 \mu \mathrm{g} \mathrm{Chl} \cdot \mathrm{mL}^{-1}\right)$ isolated from the chloroplasts of leaves recently detached (Figure 5A,B) or incubated in water for $20 \mathrm{~h}$ under high light intensity $\left(1400 \mu \mathrm{mol} \mathrm{m} \mathrm{m}^{-2} \mathrm{~s}^{-1}\right)$ at $24{ }^{\circ} \mathrm{C}$ (Figure 5C,D). The thylakoids of leaves incubated under high light intensity from plants exposed to water deficit and heat (Figure 5D) showed a slower increase in NADH-induced chlorophyll fluorescence than the thylakoids of control leaves incubated under high light intensity and those of leaves recently detached from plants, both control and those exposed to water deficit and heat. The addition of $n$-propyl gallate significantly increased the chlorophyll fluorescence level in the thylakoids of leaves incubated under high light intensity from plants exposed to water deficit and heat, whereas the effect was slight in all other conditions, indicating higher PTOX activity in the leaves under high light intensity from plants with water deficit.

Figure 5. Effect of exogenous addition of NADH $(2 \mathrm{mM})$ and $n$-propyl gallate (Pga, $1 \mathrm{mM}$ ) on the chlorophyll fluorescence level measured under low light in thylakoid membrane suspensions $\left(50 \mu \mathrm{g} \mathrm{Chl} \cdot \mathrm{mL}^{-1}\right)$ isolated from leaves recently detached (A and $\left.\mathbf{B}\right)$ or incubated in water for $20 \mathrm{~h}$ under high light intensity $\left(1400 \mu \mathrm{mol} \cdot \mathrm{m}^{-2} \cdot \mathrm{s}^{-1}\right)$ at $24{ }^{\circ} \mathrm{C}$ (C and D) from $H$. rosa-sinensis plants in control conditions and after exposure to three photoperiods $\left(18 \mathrm{~h}, 60 \mu \mathrm{mol} \cdot \mathrm{m}^{-2} \cdot \mathrm{s}^{-1}\right.$ PPFD and $\left.35^{\circ} \mathrm{C}\right)$ with reduced irrigation (water deficit). The stress photoperiods were separated by $6 \mathrm{~h}$ night-periods at $24{ }^{\circ} \mathrm{C}$. The figure shows typical curves from five independent replicates.

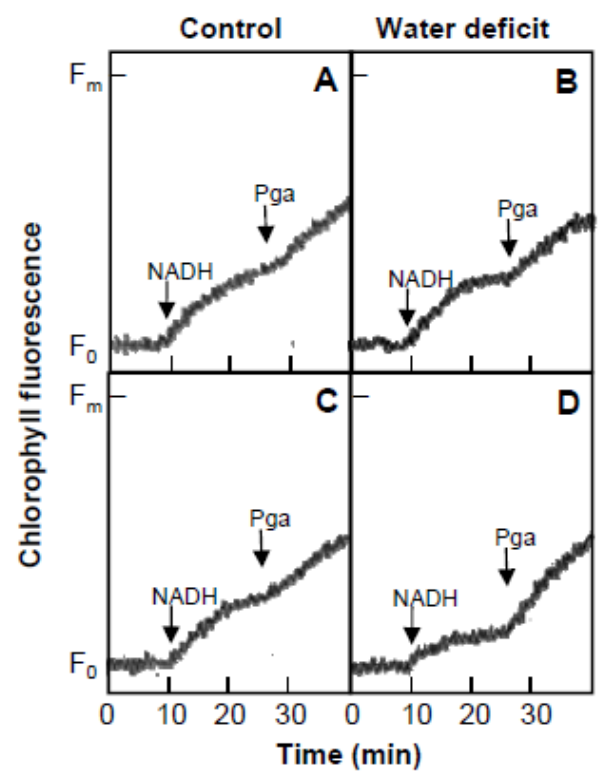


The NADH dehydrogenase activity was assayed as NADH-plastoquinone oxidoreductase (NADH-PQR) activity in thylakoid membranes of leaves recently detached or incubated under high light intensity (Figure 6). Little difference in the activity was observed in leaves recently detached from control plants and those exposed to water deficit and heat. After incubation under high light, similar activity was observed in control plants, while in water deficit plants, the activity increased two-fold compared with the recently detached leaves.

Figure 6. NADH-plastoquinone oxidoreductase (NADH-PQR) activity in the thylakoid membranes isolated from leaves recently detached (white bars) or incubated in water for $20 \mathrm{~h}$ under high light intensity $\left(1400 \mu \mathrm{mol} \cdot \mathrm{m}^{-2} \cdot \mathrm{s}^{-1}\right)$ at $24{ }^{\circ} \mathrm{C}$ (striped bars) from H. rosa-sinensis plants in control conditions and after exposure to three photoperiods $\left(18 \mathrm{~h}, 60 \mu \mathrm{mol} \cdot \mathrm{m}^{-2} \cdot \mathrm{s}^{-1} \mathrm{PPFD}\right.$ and $35^{\circ} \mathrm{C}$ ) with reduced irrigation (water deficit). The stress photoperiods were separated by $6 \mathrm{~h}$ night-periods at $24^{\circ} \mathrm{C}$. The values are the means $\pm \mathrm{SE}$ from three to four independent replicates.

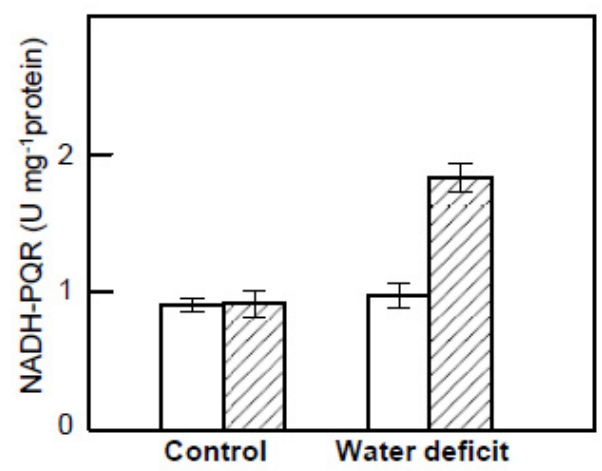

\section{Discussion}

Water deficit and heat resulted in the downregulation of linear electron transport in leaves from Hibiscus rosa-sinensis plants, as indicated by a reduction in the photochemistry efficiency of PS II and in the capacity for electron transport. The quantum yield of PS II decreased with increasing photonic flux density, because of the accumulation of electrons on the PS II acceptor side. When light was not excessive, the PS II quantum yield kept its maximum value, and the relationship between the relative electron transport rate and the light intensity was linear (Figure 3, optimum line). The relative electron transport rate fell below the values predicted by the optimum line when the PS II quantum yield decreased due to excessive light. Eventually, a saturated rate was reached, which represents the photosynthetic electron transport capacity. This capacity, as well as the PS II quantum yields and the relative electron transport rates were lower in plants exposed to water deficit and heat than in control plants. However, the decrease of the maximal quantum yield of PS II $\left(\mathrm{F}_{\mathrm{v}} / \mathrm{F}_{\mathrm{m}}\right)$ after stress photoperiods was very small, suggesting that chloroplasts are protected by mechanisms that dissipate excess excitation energy to prevent damage to the photosynthetic apparatus under adverse conditions. Regulating the flow of electrons through the photosynthetic electron transport chain is crucial to the health and survival of plants. The inhibition of photosynthetic linear electron transport, the major electron transfer pathway, could trigger alternative pathways, such as cyclic electron flow around PS I and chlororespiration [10]. Two parallel cyclic pathways exist around PS I [20], one sensitive to 
antimycin A, of which PGR5 is an essential component [21], and the other involving the NDH complex [20]. In this work, we observed that the incubation of leaves under high light intensity resulted in an increase in electron donation by NADPH and ferredoxin to plastoquinone, which was inhibited by antimycin A, in leaves of control plants, but not in leaves from plants exposed to water deficit and heat, suggesting that cyclic electron transport was stimulated by high light only in the control plants. In contrast, the activities of the chlororespiration enzymes, NDH complex and PTOX, increased after incubation under high light intensity in leaves from water deficit plants, but not from control plants, suggesting that chororespiration was stimulated in stressed plants.

Alternative routes to photosynthetic linear electron transport, such as cyclic electron flow around PS I and chlororespiratory pathways, may contribute to protecting the photosynthetic apparatus under stress conditions. It is known that cyclic electron flow increases in response to high light intensity [10,33], and the physiological relevance of NDH-mediated electron flow in chloroplasts under stress conditions has also been reported [22,35,39,41,42,44,47-50]. However, the cooperation between these pathways remains unclear [33]. The concerted action of NDH complex and PTOX would optimize the efficiency of the cyclic pathways, preventing over-reduction of the electron transfer chain $[10,51]$ and reducing the accumulation of reactive oxygen species (ROS) by recycling electrons to the plastoquinone pool and, ultimately, to oxygen through PTOX, forming water in the stroma. Additionally, these pathways contribute to balancing ATP/NADPH requirements and to generating a large proton gradient and acidification of the lumen, that play a crucial role in the regulation, preventing the light-induced inactivation of both PS I and PS II through the formation of non-photochemical quenching [10,33].

The relative importance of chlororespiration and the cyclic electron pathways regulating the flow of electrons may differ in each plant species. We have described how the PGR5-dependent cyclic pathway is more active in sun plants, whereas in shade plants, other pathways involving the NDH complex and PTOX may be more important [44,50]. Additionally, stress conditions can also affect the relative importance of these alternative electron pathways regulating the flow of electrons in plants. In this work, we have seen that plants showed higher tolerance to high illumination when there was no water deficit. In such conditions, the NDH complex and PTOX activities did not increase, while the activity of electron donation by NADPH and ferredoxin to plastoquinone increased. However, in plants suffering a water deficit, the efficiency of PS II photochemistry decreased considerably and, under high illumination, the NDH complex and PTOX activities increased. The apparent correlation between the low functioning of PS II and the upregulation of PTOX and the thylakoidal NDH complex supports a role for chlororespiration in the protection against high light when other pathways, such as cyclic electron flow around PS I, are insufficient to protect PS II.

\section{Experimental Section}

\subsection{Plant Material and Incubation Conditions}

Hibiscus rosa-sinensis plants were grown in $500 \mathrm{~mL}$ pots at $22-25{ }^{\circ} \mathrm{C}$ in a greenhouse under natural light conditions (irradiation maxima of around $800 \mu \mathrm{mol} \mathrm{m} \mathrm{m}^{-2}$ PPFD) and controlled watering to avoid drought stress until flowering (control plants). For water deficit conditions, adult plants ( $0.4 \mathrm{~m}$ height) 
were transferred to cultivation chambers with $18 \mathrm{~h}$ photoperiods of white light of low intensity ( $60 \mu \mathrm{mol} \mathrm{m} \mathrm{m}^{-2} \mathrm{~s}^{-1}$ PPFD) supplied by $40 \mathrm{~W} / 10$ Osram daylight fluorescent tubes (Augsburg, Germany) at $35{ }^{\circ} \mathrm{C}$, followed by $6 \mathrm{~h}$ night-periods at $24{ }^{\circ} \mathrm{C}$, decreasing the irrigation to $50 \mathrm{~mL} /$ day, which was applied after the start of the night period. For the high light intensity treatments, leaves were detached from control and water deficit plants after the third photoperiod and incubated for $20 \mathrm{~h}$ in Petri dishes containing water under white light of high intensity $\left(1400 \mu \mathrm{mol} \mathrm{m} \mathrm{m}^{-2} \mathrm{~s}^{-1}\right.$ PPFD) supplied by a $100 \mathrm{~W}$ Flood Osram lamp (Augsburg, Germany), at $24{ }^{\circ} \mathrm{C}$. The experiments were replicated in five independent plants for each treatment.

\subsection{Plant Water Status}

Plant water status was estimated by measuring the relative water content of leaves (RWC). Leaves were collected and immediately weighed to determine fresh weight $(\mathrm{FW})$. Leaves were then re-hydrated for $24 \mathrm{~h}$ at $4{ }^{\circ} \mathrm{C}$ in darkness to determine the turgid weight (TW) and subsequently oven-dried for $24 \mathrm{~h}$ at $85{ }^{\circ} \mathrm{C}$ to determine the dry weight (DW). The RWC was determined as $100 \times(\mathrm{FW}-\mathrm{DW}) /(\mathrm{TW}-\mathrm{DW})$.

\subsection{Isolation of Thylakoid Membranes}

Chloroplasts were isolated from leaves, as described by Quiles and Cuello [11], using an extraction buffer ( $\mathrm{pH}$ 7.6) containing $0.35 \mathrm{M}$ sucrose, $25 \mathrm{mM}$ Na-HEPES, $2 \mathrm{mM} \mathrm{Na} \mathrm{NaDTA}_{2} 2 \mathrm{mM}$ ascorbic acid, $4 \mathrm{mM}$ dithiothreitol, $10 \mathrm{mM} \mathrm{MgCl}_{2}$ and $1 \mathrm{mM}$ phenylmethylsulfonyl fluoride. As reported previously, a comparison of cytochrome $c$ oxidase-specific activity and polypeptide profiles in mitochondrial and chloroplast fractions indicated that the chloroplast preparation was essentially mitochondrion-free [52]. The chloroplasts were washed twice and osmotically broken with $10 \mathrm{mM}$ Tricine, $10 \mathrm{mM} \mathrm{NaCl}$ and $10 \mathrm{mM} \mathrm{MgCl}_{2}(\mathrm{pH}$ 7.8) buffer, as described previously [41]. The thylakoid membrane pellet was resuspended in buffer ( $\mathrm{pH} 7.5$ ) containing $200 \mathrm{mM}$ sorbitol, $130 \mathrm{mM} \mathrm{KCl}$ and $5 \mathrm{mM}$ potassium phosphate at a chlorophyll concentration of $0.4 \mathrm{mg} \mathrm{mL} \mathrm{m}^{-1}$, thus providing the thylakoid membrane suspension.

\subsection{Chlorophyll Fluorescence Measurements}

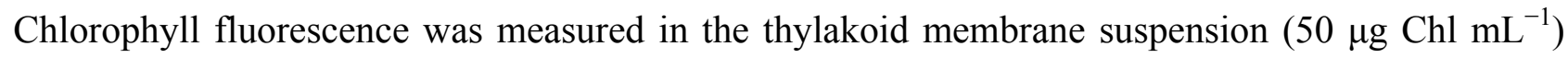
using a PAM-210 chlorophyll fluorometer (Heinz Walz GmbH, Effeltrich, Germany), and chlorophyll fluorescence was imaged, using the MINI-version of the Imaging-PAM (Heinz Walz GmbH, Effeltrich, Germany) in entire leaves. Prior to the fluorescence measurements, the leaves were dark-adapted for $30 \mathrm{~min}$. Minimal fluorescence yield $\left(\mathrm{F}_{0}\right)$ was measured at a low frequency of pulse modulated measuring light, while maximal fluorescence yield $\left(\mathrm{F}_{\mathrm{m}}\right)$ was measured with the help of a saturation pulse. The maximal quantum yield of PS II $\left(\mathrm{F}_{\mathrm{v}} / \mathrm{F}_{\mathrm{m}}\right)$ was calculated using the PAM fluorometer software (Heinz Walz GmbH: Effeltrich, Germany, 2006).

Light response curves were made by illuminating the entire leaves with actinic light of different intensities $\left(60,90,120,150,210,310,440,600,850\right.$ and $1250 \mu \mathrm{mol} \mathrm{m} \mathrm{m}^{-2} \mathrm{~s}^{-1}$ PAR), with 2 min illumination periods at each intensity. After each illumination period, a saturation pulse was applied to 
determine the quantum yield of PS II and the relative electron transport rate, all of which were calculated using the PAM fluorometer software.

\subsection{NADH-Plastoquinone Oxidoreductase Activity}

The NADH-plastoquinone oxidoreductase (NADH-PQR) activity was determined, as described by Gamboa et al. [50], by measuring NADH oxidation at $340 \mathrm{~nm}$ in a Perkin Elmer (Germany) spectrophotometer at $25{ }^{\circ} \mathrm{C}$. One unit (U) of enzymatic activity is defined as the amount of enzyme preparation that oxidized $1 \mu \mathrm{mol}$ of substrate $(\mathrm{NADH})$ per minute in the reaction conditions. The extinction coefficient of $6.22 \mathrm{mM}^{-1} \mathrm{~cm}^{-1}$ at $340 \mathrm{~nm}$ was used to calculate the NADH oxidation rate.

\subsection{Other Determinations}

Protein was quantified using the method of Lowry et al. [53] after precipitation with $10 \%(w / v)$ trichloroacetic acid. Chlorophyll was determined by Lichtenthaler and Wellburn's [54] method using $80 \%(v / v)$ acetone as solvent. Densitometric analysis and estimation of the polypeptide molecular masses were performed by an ACTIB 1D digital image analyzer (Microptic, Barcelona, Spain).

\section{Conclusions}

The relative importance of chlororespiration and the cyclic electron pathways in the tolerance of photosynthesis to high illumination differs under stress conditions. When plants are not subjected to stress, the contribution of chlororespiration to regulating photosynthetic electron flow is not relevant, and another pathway, such as the ferredoxin-mediated cyclic pathway, is more important. However, when PS II activity is inhibited by water deficit and heat, chlororespiration, together with other routes of electron input to the electron transfer chain, is probably essential, not only to support cyclic electron flow and ATP production in chloroplasts, but also to reduce the formation of ROS by preventing over-reduction of the plastoquinone pool in the chloroplasts.

\section{Acknowledgments}

We thank J. Gamboa for assistance in the laboratory. This work was supported by the Spanish Ministry of Science and Innovation (grant BFU2008-00331).

\section{References}

1. Berry, J.A.; Björkman O. Photosynthetic response and adaptation to temperature in higher plants. Annu. Rev. Plant Physiol. 1980, 31, 491-543.

2. Powles, S.B. Photoinhibition of photosynthesis induced by visible light. Annu. Rev. Plant Physiol. 1984, 35, 15-44.

3. Chaves, M.M.; Flexas, J.; Pinheiro, C. Photosynthesis under drought and salt stress: Regulation mechanisms from whole plant to cell. Ann. Bot. 2009, 103, 551-560.

4. Fork, D.C.; Herbert, S.K. Electron transport and photophosphorylation by Photosystem I in vivo in plants and cyanobacteria. Photosynth. Res. 1993, 36, 149-168. 
5. Bukhov, N.; Carpentier, R. Alternative photosystem I-driven electron transport routes: Mechanisms and functions. Photosynth. Res. 2004, 82, 17-33.

6. Johnson, G.N. Cyclic electron transport in C3 plants: Fact or artifact? J. Exp. Bot. 2005, 56, 407-416.

7. Bennoun, P. Evidence for a respiratory chain in the chloroplast. Proc. Natl. Acad. Sci. USA 1982, 79, 4352-4356.

8. Bennoun, P. Chororespiration revised: Mitochondrial-plastid interaction in Chlamydomonas. Biochim. Biophys. Acta 1994, 1186, 59-66.

9. Peltier, G.; Cournac, L. Chlororespiration. Annu. Rev. Plant Biol. 2002, 53, 523-550.

10. Rumeau, D.; Peltier, G.; Cournac, L. Chlororespiration and cyclic electron flow around PSI during photosynthesis and plant stress response. Plant Cell Environ. 2007, 30, 1041-1051.

11. Quiles, M.J.; Cuello, J. Association of ferredoxin-NADP oxidoreductase with the chloroplastic pyridine nucleotide dehydrogenase complex in barley leaves. Plant Physiol. 1998, 117, 235-244.

12. Sazanov, L.A.; Burrows, P.A.; Nixon, P.J. The plastid ndh genes code for an NADH-specific dehydrogenase: Isolation of a complex I analogue from pea thylakoid membranes. Proc. Natl. Acad. Sci. USA 1998, 95, 1319-1324.

13. Quiles, M.J.; García, A.; Cuello, J. Separation by blue-native PAGE and identification of the whole NAD $(\mathrm{P}) \mathrm{H}$ dehydrogenase complex from barley stroma thylakoids. Plant Physiol. Biochem. 2000, 38, 225-232.

14. Quiles, M.J. Regulation of the expression of chloroplast ndh genes by light intensity applied during oat plant growth. Plant Sci. 2005, 168, 1561-1569.

15. Rumeau, D.; Becuwe-Linka, N.; Beyly, A.; Louwagie, M.; Garin, J.; Peltier, G. New subunits $\mathrm{NDH}-\mathrm{M},-\mathrm{N}$, and $-\mathrm{O}$, encoded by nuclear genes, are essential for plastid Ndh complex functioning in higher plants. Plant Cell 2005, 17, 219-232.

16. Ifuku, K.; Endo, T.; Shikanai, T.; Aro, E.M. Structure of the chloroplast NADH dehydrogenase-like complex: Nomenclature for nuclear-encoded subunits. Plant Cell Physiol. 2011, 52, 1560-1568.

17. Aluru, M.R.; Rodermel, S.R. Control of chloroplast redox by the IMMUTANS terminal oxidase. Physiol. Plant. 2004, 120, 4-11.

18. Kuntz, M. Plastid terminal oxidase and its biological significance. Planta 2004, 218, 896-899.

19. Sun, X.; Wen, T. Physiological roles of plastid terminal oxidase in plant stress responses. J. Biosci. 2011, 36, 951-956.

20. Joët, T.; Cournac, L.; Horvath, E.M.; Medgyesy, P.; Peltier, G. Increased sensitivity of photosynthesis to antimycin A induced by inactivation of the chloroplast ndhB gene. Evidence for a participation of the NADH-dehydrogenase complex to cyclic electron flow around photosystem I. Plant Physiol. 2001, 125, 1919-1929.

21. Munekage, Y.; Hojo, M.; Meurer, J.; Endo, T.; Tasaka, M.; Shikanai, T. PGR5 is involved in cyclic electron flow around photosystemI and is essential for photoprotection in Arabidopsis. Cell 2002, 110, 361-371.

22. Munekage, Y.; Hashimoto, M.; Miyake, C.; Tomizawa, K.; Endo, T.; Tasaka, M.; Shikanai, T. Cyclic electron flow around photosystem I is essential for photosynthesis. Nature 2004, 429, 579-582. 
23. DalCorso, G.; Pesaresi, P.; Masiero, S.; Aseeva, E.; Schünemann, D.; Finazzi, G.; Joliot, P.; Barbato, R.; Leister, D. A complex containing PGRL1 and PGR5 is involved in the switch between linear and cyclic electron flow in Arabidopsis. Cell 2008, 132, 273-285.

24. Hebert, S.K.; Fork, D.C.; Malkin, S. Photoacoustihc measurements in vivo of energy storage by cyclic electron flow in algae and higher plants. Plant Physiol. 1990, 94, 926-934.

25. Havaux, M.; Greppin, H.; Strasser, R.J. Functioning of photosystem I and photosystem II in pea leaves exposed to heat stress in the presence of absence of light, analysis using in vivo fluorescence, absorbency, oxygen and photoacoustic measurements. Planta 1991, 186, 88-98.

26. Bendall, D.S.; Manasse, R.S. Cyclic photophosphorylation and electron transport. Biochim. Biophys. Acta 1995, 1229, 23-38.

27. Joët, T.; Cournac, L.; Peltier, G.; Havaux, M. Cyclic electron flow around photosystem I in C3 plants. In vivo control by the redox state of chloroplasts and involvement of the NADHdehydrogenase complex. Plant Physiol. 2002, 128, 760-769.

28. Joliot, P.; Joliot, A. Cyclic electron transfer in plant leaf. Proc. Natl. Acad. Sci. USA 2002, 99, 10209-10214.

29. Joliot, P.; Joliot, A. Cyclic electron flow in C3 plants. Biochim. Biophys. Acta 2006, 1757, 362-368.

30. Golding, A.J.; Johnson, G.N. Down-regulation of linear and activation of cyclic electron transport during drought. Planta 2003, 218, 107-114.

31. Golding, A.J.; Finazzi, G.; Jhonson, G.N. Reduction of the thylakoid electron transport chain by stromal reductants, evidence for activation of cyclic electron transport upon dark adaptation or under drought. Planta 2004, 220, 356-363.

32. Breyton, C.; Nandha, B.; Johnson, G.N.; Joliot, P.; Finazzi, G. Redox modulation of cyclic electron flow around photosystem I in C3 plants. Biochemistry 2006, 45, 13465-13475.

33. Joliot, P.; Johnson, G.N. Regulation of cyclic and linear electron flow in higher plants. Proc. Natl. Acad. Sci. USA 2011,108, 13317-13322.

34. Herbert, S.K.; Martin, R.E.; Fork, D.C. Light adaptation of cyclic electron transport through photosystem I in the cyanobacterium Synechococcus sp. PCC 7942. Photosynth. Res. 1995, 46, 277-285.

35. Endo, T.; Shikanai, T.; Takabayashi, A.; Asada, K.; Mi, H.; Sato, F. The role of chloroplastic $\mathrm{NAD}(\mathrm{P}) \mathrm{H}$ dehydrogenase in photoprotection. FEBS Lett. 1999, 457, 5-8.

36. Teicher, H.B.; Moller, B.L.; Scheller, H.V. Photoinhibition of photosystem I in field-grown barley (Hordeum vulgare L.): Induction, recovery and acclimation. Photosynth. Res. 2000, 64, 53-61.

37. Casano, L.M.; Martín, M.; Sabater, B. Hydrogen peroxide mediates the induction of chloroplastic NDH complex under photooxidative stress in barley. Plant Physiol. 2001, 125, 1450-1458.

38. Rizhsky, L.; Hallak-Herr, E.; van Breusegem, F.; Rachmilevitch, S.; Barr, J.E.; Rodermel, S.; Inze, D.; Mittler, R. Double antisense plants lacking ascorbate peroxidase and catalase are less sensitive to oxidative stress than single antisense plants lacking ascorbate peroxidase or catalase. Plant J. 2002, 32, 329-342.

39. Quiles, M.J.; López, N.I. Photoinhibition of photosystems I and II induced by exposure to high light intensity during oat plant growth. Effects on the chloroplast NADH dehydrogenase complex. Plant Sci. 2004, 166, 815-823. 
40. Streb, P.; Josse, E.M.; Gallouët, E.; Baptist, F.; Kuntz, M.; Cornic, G. Evidence for alternative electron sinks to photosynthetic carbon assimilation in the high mountain plant species Ranunculus glacialis. Plant Cell Environ. 2005, 28, 1123-113.

41. Quiles, M.J. Stimulation of chlororespiration by heat and high light intensity in oat plants. Plant Cell Environ. 2006, 29, 1463-1470.

42. Díaz, M.; De Haro, V.; Muñoz, R.; Quiles, M.J. Chlororespiration is involved in the adaptation of Brassica plants to heat and high light intensity. Plant Cell Environ. 2007, 30, 1578-1585.

43. Tallón, C.; Quiles, M.J. Acclimation to heat and high light intensity during the development of oat leaves increases the NADH DH complex and PTOX levels in chloroplasts. Plant Sci. 2007, 173, $438-445$.

44. Ibañez, H.; Ballester, A.; Muñoz, R.; Quiles, M.J. Chlororespiration and tolerance to drought, heat and high illumination. J. Plant Physiol. 2010, 167, 732-738.

45. Paredes, M.; Quiles, M.J. Stimulation of chlororespiration by drought under heat and high illumination in Rosa meillandina. J. Plant Physiol. 2013, 170, 165-171.

46. Joët, T.; Genty, B.; Josse, E.M.; Kuntz, M.; Cournac, L.; Peltier, G. Involvement of a plastid terminal oxidase in plastoquinone oxidations as evidenced by expression of the Arabidopsis thaliana enzyme in tobacco. J. Biol. Chem. 2002, 277, 31623-31630.

47. Li, X.G.; Duan, W.; Meng, Q.W.; Zou, Q.; Zhao, S.J. The function of chloroplastic NAD(P)H dehydrogenase in tobacco during chilling stress under low irradiance. Plant Physiol. 2004, 45, $103-108$.

48. Wang, P.; Duan, W.; Takabayashi, A.; Endo, T.; Shikanai, T.; Ye, J.Y.; Mi, H. Chloroplastic $\mathrm{NAD}(\mathrm{P}) \mathrm{H}$ dehydrogenase in tobacco leaves functions in alleviation of oxidative damage caused by temperature stress. Plant Physiol. 2006,141, 465-474.

49. Saura, P.; Quiles, M.J. Assessment of photosynthesis tolerance to herbicides, heat and high illumination by fluorescence imaging. Open Plant Sci. J. 2009, 3, 7-13.

50. Gamboa, J.; Muñoz, R.; Quiles, M.J. Effects of antimycin A and n-propyl gallate on photosynthesis in sun and shade plants. Plant Sci. 2009, 177, 643-647.

51. Havaux, M.; Rumeau, D.; Ducruet, J.M. Probing the FQR and NDH activities involved in cyclic electron transport around photosystem I by the "afterglow" luminescence. Biochim. Biophys. Acta 2005, 1709, 203-213.

52. Quiles, M.J.; García, A.; Cuello, J. Comparison of the thylakoidal NAD(P)H dehydrogenase complex and the mitochondrial complex I separated from barley by blue-native PAGE. Plant Sci. 2003, 164, 541-547.

53. Lowry, O.H.; Rosebrough, N.J.; Farr, A.L.; Randall, R.J. Protein measurement with the Folin phenol reagent. J. Biol. Chem. 1951, 193, 265-275.

54. Lichtenthaler, H.K.; Wellburn, A.R. Determinations of total carotenoids and chlorophylls a and b of leaf extracts in different solvents. Biochem. Soc. Trans. 1983, 11, 591-592.

(C) 2013 by the authors; licensee MDPI, Basel, Switzerland. This article is an open access article distributed under the terms and conditions of the Creative Commons Attribution license (http://creativecommons.org/licenses/by/3.0/). 